\title{
Intracranial venous sinus thrombosis as unusual presentation of Bing-Neel syndrome: case illustration
}

\author{
Rosa Morabito, MD, ${ }^{1}$ Giovanni Grasso, MD, PhD, ${ }^{2}$ Valeria Barresi, MD, ${ }^{3}$ \\ Paolo La Spina, MD, ${ }^{4}$ Giada Garufi, MD, ${ }^{5}$ Elisabetta Alafaci, MD, ${ }^{6}$ \\ Francesco M. Salpietro, MD, ${ }^{5}$ Marcello Longo, MD, ${ }^{1}$ Francesca Granata, MD, ${ }^{1}$ and \\ Concetta Alafaci, MD ${ }^{5}$
}

\begin{abstract}
${ }^{1}$ Neuroradiology Unit, Department of Biomedical Sciences and Morphological and Functional Images, and Departments of ${ }^{3}$ Human Pathology, ${ }^{4}$ Neurology, ${ }^{5}$ Neurosurgery, and ${ }^{6}$ Oncology, University of Messina; and ${ }^{2}$ Section of Neurosurgery, Department of Experimental Biomedicine and Clinical Neurosciences (BIONEC), University of Palermo, Italy
\end{abstract}

https://thejns.org/doi/abs/10.3171/2016.9.JNS161678

KEY WORDS Bing-Neel syndrome; central nervous system; Waldenstrom macroglobulinemia; vascular disorders

$\mathrm{W}$ ALDENSTROM macroglobulinemia, a lymphoplasmacytic lymphoma, accounts for $2 \%$ of monoclonal gammopathies. ${ }^{2,4,5}$ Neurological complications occur in $25 \%$ of these patients ${ }^{5}$ with peripheral nerve infiltration or serum hyperviscosity syndrome. ${ }^{1,3,4}$ Direct malignant infiltration of the brain is rare and is referred to as Bing-Neel syndrome., $1,3,5$

A 42-year-old woman presented with progressive blurred vision, vertigo, and headache. MRI showed bilateral intraocular protrusion of the optic nerve head and right transverse sinus thrombosis (Fig. 1). Low-molecular-weight heparin was administered without symptom relief. Additional MRI showed left frontoparietal arachnoid space obliteration by pathological tissue, and infiltration of the sagittal and right transverse sinuses. After Gd administration, we observed diffuse enhancement of the dura in the left cerebral hemisphere and subdural and epicranial soft-tissue infiltration (Fig. 2). A biopsy of the extra-axial tissue was performed. Histological examination showed a neoplasm composed of large cells with ovoid nuclei associated with nonneoplastic lymphocytes. Frequent mitotic figures were observed in the large cells. The large neoplastic cells were positive for CD20, bcl-2, bcl-6, and MUM1 and negative for CD10 and CD30 (Fig. 3). Accordingly, a diffuse infiltrative form of Bing-Neel syndrome was diagnosed. The patient was treated with 3 cycles of rituximab, dexamethasone, methotrexate HD, and cytarabine. Osmotic and steroid therapies were under- taken. However, a few days after the diagnosis she died of respiratory failure before initiation of brain radiotherapy.

To our knowledge, this is the first report of diffuse neoplastic infiltration of the principal intracranial venous sinuses in Bing-Neel syndrome. The absence of specific symptoms makes diagnosis challenging. Clinical and neuroradiological evaluations can anticipate the diagnosis and allow early treatment. Therapeutic modalities, such as chemotherapy and radiotherapy alone or in combination, have been proposed for BingNeel syndrome treatment. However, the number of successfully treated cases is insufficient to suggest any statistical conclusion about the superiority of one treatment modality over another.

\section{References}

1. Grewal JS, Brar PK, Sahijdak WM, Tworek JA, Chottiner EG: Bing-Neel syndrome: a case report and systematic review of clinical manifestations, diagnosis, and treatment options. Clin Lymphoma Myeloma 9:462-466, 2009

2. Imai F, Fujisawa K, Kiya N, Ninomiya T, Ogura Y, Mizoguchi Y, et al: Intracerebral infiltration by monoclonal plasmacytoid cells in Waldenstrom's macroglobulinemia-case report. Neurol Med Chir (Tokyo) 35:575-579, 1995

3. Kim HJ, Suh SI, Kim JH, Kim BJ: Brain magnetic resolution imaging to diagnose Bing-Neel syndrome. J Korean Neurosurg Soc 46:588591, 2009

4. Ly KI, Fintelmann F, Forghani R, Schaefer PW, Hochberg EP, Hochberg FH: Novel diagnostic 
approaches in Bing-Neel syndrome. Clin Lymphoma Myeloma Leuk 11:180-183, 2011

5. Simon L, Fitsiori A, Lemal R, Dupuis J, Carpentier B, Boudin L, et al: Bing-Neel syndrome, a rare complication of Waldenström macroglobulinemia: analysis of 44 cases and review of the literature. A study on behalf of the French Innovative Leukemia Organization (FILO). Haematologica 100:1587-1594, 2015

\section{Disclosures}

The authors report no conflict of interest concerning the materials or methods used in this study or the findings specified in this paper.

\section{Author Contributions}

Conception and design: C Alafaci, Salpietro. Acquisition of data: La Spina. Analysis and interpretation of data: Barresi, E Alafaci, Longo, Granata. Drafting the article: Morabito, Grasso, Garufi.

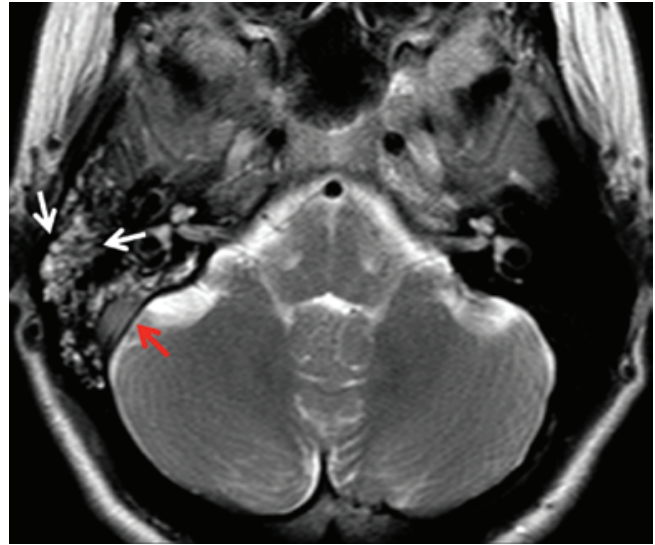

FIG. 1. Axial T2-weighted MR image at clinical onset showing right otomastoiditis (white arrows) associated with right transverse sinus thrombosis (red arrow). Figure is available in color online only.
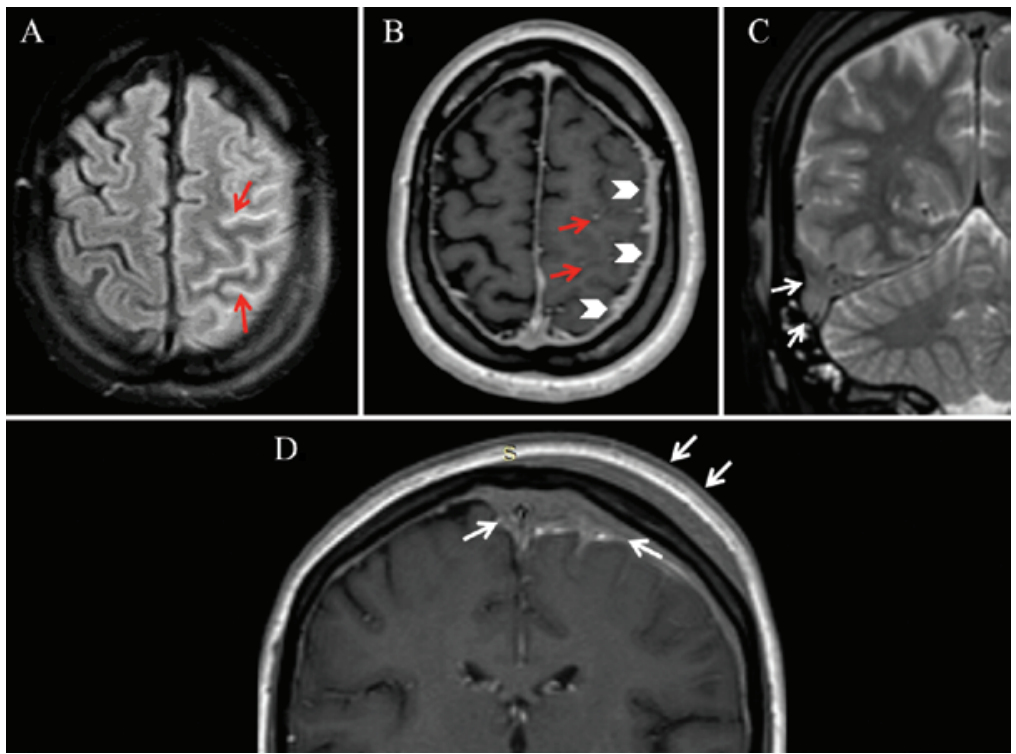

FIG. 2. Early MRI follow-up. A: Axial FLAIR image showing left frontoparietal arachnoid space obliteration (red arrows). B: Axial Gd-enhanced T1-weighted MR image revealing extensive dura mater thickening (arrowheads) with mild leptomeningeal enhancement (red arrows). C: Coronal Gd-enhanced T1-weighted image showing right transverse sinus neoplastic infiltration (arrows). D: Coronal Gd-enhanced T1-weighted image showing superior sagittal sinus and subdural and epicranial soft-tissue neoplastic infiltration (arrows) with intense enhancement. Figure is available in color online only.

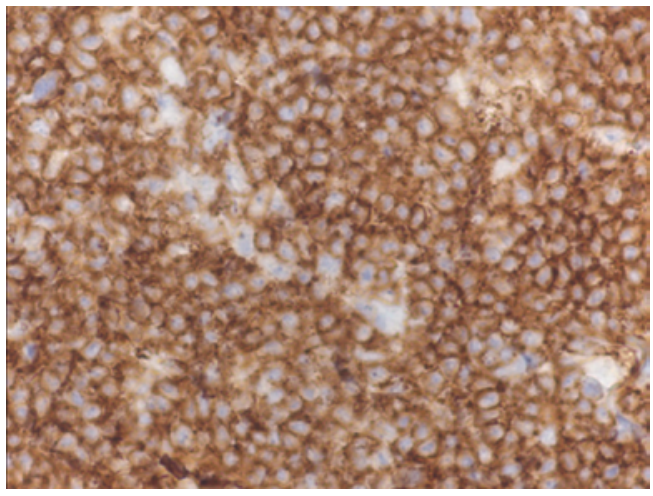

FIG. 3. Histological examination. Densely cellular neoplasm composed of large cells with ovoid nucleoli. Cells are CD20 positive at immunohistochemistry. CD20 stain. Original magnification $\times 400$. Figure is available in color online only. 